\title{
Modernidad, identidad cultural y medios de comunicación
}

\author{
María de la Luz Casas Pérez \\ Instituto Tecnológico y de Estudios Superiores \\ de Monterrey (ITESM), campus Morelos
}

EN CEREMONIA celebrada el 17 de diciembre de 1992 en la residencia oficial de Los Pinos, el Presidente de México Carlos Salinas de Gortari firma simultáneamente con sus homólogos, el Presidente George Bush de los Estados Unidos, y el Primer Ministro de Canadá, Brian Mulroney, el texto definitivo del Tratado de Libre Comercio de América del Norte, acto con el que culmina el período de negociaciones comerciales entre los gobiernos de los tres países comprometidos con dicho acuerdo. Con este simple pero significativo acto, México cruza el umbral de la puerta de la modernidad.

El presente trabajo tiene como objetivo analizar una vez más - entre otras cosas - nuestra condición de país premoderno por sus tradiciones, moderno por decreto y posmoderno por su efervescencia cultural. Qué tan modernos somos, depende en gran medida de cómo nos consideramos, y en ese sentido, del perpetuo forcejeo entre un pasado que nos arrastra y un futuro que nos promete. Nuestra identidad como pueblo y nuestra identidad como Nación, se funden en lo que parece ser el último reducto que nos diferencia en un mundo que tiende a la globalización y a la fusión de las identidades culturales. En esta encrucijada, los medios de comunicación, portadores del discurso y actores fundamentales en la instrumentación de la mecánica del cambio, renuevan su papel de aparentes espectadores silenciosos, testigos mudos de la industrialización, de la tecnologización, y de la explosión informativa característica de cualquier sociedad moderna. ¿Cuáles son, sin embargo, los nexos que conectan el discurso de la modernidad, con el de la identidad, no nacional sino cultural de los pueblos, y con el proyecto globalizador que circula libremente a través de los medios de comunicación? ¿Cómo es que el Estado articula los mecanismos de modernización y los da a 
conocer, sin aparente contradicción con los intereses de los movimientos y de los sujetos sociales, y en consonancia con una utopía alcanzable para todos? Esa es la temática que intentaré explorar en las próximas páginas.

\section{¿Premodernos, modernos o posmodernos?}

¿Qué es la modernidad, sino un recurso de la razón para crear la ilusión humana de haber alcanzado un estado de avance? ¿Qué es la historia, sino un recurso del hombre para explicar su tránsito por las distintas etapas de su evolución, a las que ha dado burdamente en calificar de premodernas, modernas y ahora posmodernas? ¿Qué es la modernidad, sino un escurridizo precepto conceptual que utilizamos a voluntad para exigir derechos y evadir responsabilidades?

La modernidad es producto de la racionalidad humana, escollo filosófico e intelectual que garantiza racionalmente la explicación de un estadio en el que el hombre deviene distinto de sí mismo, originador de procesos y de relaciones; la modernidad viene siendo hija natural del siglo de las luces, producto de la secularización de la vida cotidiana y del momento en el que la racionalidad toma las riendas de la existencia humana, para declararse única e incuestionable controladora de los destinos de las sociedades y de las naciones. A bordo de la razón, el hombre deja atrás los nubarrones negros de las sociedades tradicionales y primitivas en las que su destino era determinado por fuerzas oscuras, e iluminado por un panorama espiritual prometedor plagado de destellos contractualistas, se obliga a navegar en las aguas de la modernidad, guiado por el faro del progreso.

Si hemos de intentar descubrir qué es eso que hoy llamamos modernidad, quizás nos sea de suma utilidad recordar las palabras de Marshall Berman en su Brindis por la modernidad (1987:67):

Todos los hombres y mujeres del mundo comparten hoy una forma de experiencia vital -experiencia del espacio y el tiempo del ser y de los otros, de las posibilidades y los peligros de la vida - a la que llamaré modernidad. Ser modernos es encontrarnos en un medio ambiente que nos promete aventura, poder, alegrí, crecimiento, transformación de nosotros mismos y del mundo-y que al mismo tiempo amenaza con destruir todo lo que tenemos, todo lo que sabemos, lo que somos. Los ambientes y las experiencias modernas cruzan todas las fronteras de la geografía y la etnicidad, de las clases y la nacionalidad, de la religion y la ideologra: en este sentido, puede decirse que la modernidad une a toda la humanidad. No obstante esta unión es paradojica, es una 
unión de la desunión: nosarroja a unremolinode desintegracióny renovación perpetuas, de conflicto y de contradicción, de ambigüedad y angustia. Ser modernos es ser parte de un universo en el que, como dijo Marx, todo lo que es sólido se evapora en el aire.

¿Es este un remolino en el que nos encontramos inmersos, prácticamente sin salida? ¿Será la condición moderna un estadio obligado del hombre en su permanente búsqueda por una noción utópica de progreso? El progreso, concebido como avance, condición de movilización de las sociedades humanas, implica como indica Berman, transformación, aventura, y crecimiento. Preconiza salud, felicidad, y mejoramiento, y sin embargo, llega no pausada y placenteramente sino con súbitos y dolorosos quebrantamientos. Modernidad, crisis y progreso son los términos de la ecuación que distingue a nuestro tiempo. (Subirats, 1987:218).

Cada sociedad busca poner en marcha sus procesos de modernización, en el afán de desarrollar su propia ecuación de modernidad, crisis y progreso; el problema es que dichos procesos de modernización, en la era contemporánea se encuentran supeditados no sólo a los impulsos modernizadores propios de cada contexto social, sino a los avatares de un contexto globalizador internacional que obliga a las sociedades menos modernas a seguir ritmos modernizadores exógenos a sus patrones originales de desarrollo. Así por ejemplo, nuestras sociedades latinoamericanas, desde su gestación como naciones, se sintieron condicionadas a voltear la mirada a Europa, y a seguir sus patrones de modernidad y de progreso, y en la era moderna, - léase que ya hemos avanzado y nos hemos modernizadovolteamos hacia nuevas fórmulas utópicas de modernidad, que tal y como nos plantea la nueva condición moderna, representan un avance respecto de etapas anteriores. De tal suerte que según José Joaquín Brunner, América Látina en su desarrollo contemporáneo, experimenta una serie de procesos contradictorios y heterogéneos de conformación de una modernidad tardía, construida en condiciones de acelerada internacionalización de los mercados a nivel mundial (Brunner, 1990). En otras palabras iSerá que la corriente de modernidad nos lleva inexorablemente hacia algún destino al que necesariamente tenemos que arribar, y al que nos hemos incorporado tardíamente? ¿Hemos llegado tarde al festín de la modernidad como indica Octavio Paz? ¿Deseamos llegar? ¿O será que hacemos esfuerzos por resistir nuestra incorporación al bloque internacional de la modernidad? Quizá sea por ello que los procesos modernizadores latinoamericanos se encuentran especialmente cargados de brotes violentos y desgarradores. Carlos Fuentes(1990), ha apuntado al respecto, que somos un continente en búsqueda desesperada de 
su modernidad, pero demasiadas veces hemos reaccionado violentamente contra semejante búsqueda haciendo intentos por regresar a nuestro pasado tradicional. Esto nos lleva a considerar que América Latina, sin embargo, y mucho a su pesar, se encuentra encadenada de mil maneras a la modernidad (Brunner, 1992:29).

Nuestro país viene haciendo súbitos y dolorosos intentos por acercarse a la modernidad; y en el proceso ha dejado de lado importantes elementos para el desarrollo social que se manifiestan en pobreza, desarraigo, marginación, y en general en nuevas formas de intolerancia y de disidencia producto del acelerado impulso modernizador al que nos ha obligado el Estado.

Esta modernidad, que se derrama como un alud incontenible, aparece acompanada de la imagen o convencimiento de que los elementos positivos de la misma serán mayores que los negativos; queel progreso implícitoaésta derramarásu cadena benéfica de forma irrefrenable sobre la sociedad mexicana en forma total, asistiéndose a un verdadero ‘despegue social y político' (...) (Fernández Reyes, 1993).

En su camino a la modernidad, México ha intentado varios acercamientos, ha puesto en marcha distintos procesos modernizadores, siendo el más importante de ellos, el de la modernización económica, y muy particularmente su entrada a la comunidad económica de América del Norte, a través de la firma del Tratado Trilateral de Libre Comercio con Estados Unidos y Canadá (TLC) como vía para acceder a una modernización económica más acelerada. Sin embargo, como indica Huntington (1972), hay que tener cuidado en creer que porque una sociedad ha puesto en marcha procesos de modernización, que producen efectos políticos relacionados con la modernización social, cultural y económica, se ha logrado la transición de un Estado tradicional a uno moderno. Dice Huntington, citado por Fernández Reyes (1993:10):

En la práctica, la modernización siempre lleva implícitoun cambioen un sistema político tradicional, y por lo general su desintegración, pero no necesariamente un avance significativo hacia un sistema político moderno.

Un proceso de modernización integral, implicaría como correlato natural mecanismos modernizadores igualmente importantes en la arena política, sin embargo, el Estado mexicano rompió con la identidad tradicional entre las esferas de la política y la economía, proceso por el cual el Estado vigilabay protegía todos los 
aspectos de la vida económica; en sentido estricto, nos referimos aquí a las formas de modernización que habían asignado al Estado un papel como garante del desarrollo y la modernidad, así como de salvaguarda de intereses e identidad de todos los sectores sociales. Se trataba de una identidad conveniente y estable para el sistema político, el cual absorbía las tensiones de una esfera remitiéndolas a la otra (Fernández Reyes, 1993:11).

De pronto, los mecanismos modernizadores giraron ciento ochenta grados para proponer la desestabilización, desconcentración, descentralización y liberación económica en medio de una situación particularmente incierta en términos políticos.

En julio de 1988, el régimen/sistema político mexicano comenzó la transición, una transición que, de acuerdo con Antonio Camou, continúa irresuelta hasta la fecha. Según este autor, el proceso transicional del régimen/sistema se intentó orientar en términos de una democratización política en sentido amplio, lo cual sin embargo ha producido regresos o retrocesos de carácter autoritario (Camou, 1992).

La modernización debe ser un proceso-de ahíque hayamos hablado, desde hace tiempo, de las paradojas de la modernización-que necesariamente vaya hacia atrás, para recoger lo que se perdio o simplemente se ha debilitado, y vaya también hacia adelante, para atender rezagos que ya están, y para anticipar el futuro (Ruiz Massieu, 1990).

La modernización del partido en el poder ha sido una reiterada aspiración que cobró mayor urgencia a resultas de la crisis económica; la pérdida relativa de la capacidad de transformación del PRI frente a otras instituciones políticas, y del desarrollo de una sociedad más plural, descentralizada, analítica, informada y crítica (Ruiz Massieu, 1990:30). Lo anterior dio como resultado que el propio presidente Carlos Salinas de Gortari indicara los derroteros a seguir cuando declaró:

La modernización del PRI es una tarea colectiva. Cambiaremos, pero para fortalecernos. Cambiaremos sí, pero no a costa de nuestra fuerza electoral y de nuestra unidad interna, garantías de avance democrático y revolucionario para el paír. ${ }^{1}$

1 Citado como preámbulo al capítulo sobre el PRI, por Ruiz Massieu (1990). 
Yesque, siasíse quiere, se pretendía consumarla ruptura de una antigua modernidad (FernándezReyes, 1993:11). Las declaraciones del presidente sentaron las acciones a tomar; un hecho significativo terminó por concretar la dirección del proceso modernizador en marcha:

En diciembre de 1991, el gobierno mexicano calladamente incendió las boletas electorales de las elecciones presidenciales de 1988. Este acto, que aseguraba que ningún gobierno posterior pudiera probar la naturaleza fraudulenta de la elección de Carlos Salinas de Gortari, fue el intento de cerrar la puerta al pasado. En la recta final para laculminación de un tratadode libre comerciopara América del Norte (TLC), resultaba crucial que ningún gobierno mexicano pudiera probar que tanto engaño y fraude se había requerido para poner en marcha la posibilidad de un libre comercio con los Estados Unidos (Traynor, 1992).

La dirección en términos de política modernizadora estaba dada desde principios de la década de los ochenta, en que la reestructuración capitalista internacional había iniciado el movimiento de la liberalización e integración de los mercados; lo que hacía falta era dar los pasos firmes para el proyecto de transformación social, incluida la transformación política. Según indica Otto Fernández Reyes (1993:13), la naturaleza de los tradicionales mecanismos de cooptación, mediación y representación sufrieron una modificación sustancial, las elecciones de 1988 representaron un parteaguas, proyectando un panorama ejemplar de acción cívica, poniendo en entredicho los cimientos sobre los que se sustentaba la modernización autoritaria, sin llegar a escindir sin embargo, el alcance de los cambios estructurales propuestos por la clase política dominante. Sin embargo, no lograron aminorar los destinos que para México ya se encontraban trazados.

Hoy en día, esa clase política que desarrolla los cambios, ha logrado asegurarse de que no hay ninguna amenaza real que esté posibilitada - hasta el momento para relevarla total o parcialmente, en ese sentido es que la modemización se vuelve autoritaria. Es decir, presupone que la clase política se asume como la depositaria de la transición política, y como aquella que resolverá sin ningún problema los cauces de la nueva modernidad necesaria para el México del fin del milenio.

Impuesta desde arriba y autoritariamente, la modernización se presenta como una destrucción y una caída para los más, como una edad de oro de progreso y poder para los menos. A esta sociedad desde siempre dual y desgarrada, se la quiere una vez más dividir en dos sociedades, la de los incluidos y la de los excluidos, la de los establecidos 
y la de los nomás acampados, según la moderna sociedad dual que la actual reestructuración mundial del capitalismo quiere imponer en todos los países (Gilly, 1988:33).

Resulta connatural para muchos, pensar en que cualquier proyecto modernizador, aún cuando sea específico implica una reestructuración a muchos niveles de todas las esferas que conforman parte de la vida social; la política, la economía, la cultura. El movimiento brusco de una de las esferas, necesariamente afecta a las demás. Los mercados económicos traen consigo la posibilidad de consumir nuevas mercancías, el consumo de productos nuevos patrones de vida, los sectores sociales se recomponen, o dicho de otra manera, la modernización enfrenta formas nuevas y viejas de reconstitución de la movilización y subjetivización de los actores y sujetos sociales (Fernández Reyes, 1993:10).

Por un lado, los estados nacionales establecen programas de modernización que imprimen dirección a las políticas modernizadoras, y por otro los mecanismos instrumentales de la modernidad se ponen en operación para permitir la transformación de la sociedad; en este sentido comulgamos con Touraine (1990), quien insiste en lanecesidad de separar la modernidad comoobjetivo, de la modernización como mecanismo.

Por otro lado, en el caso de México, descartamos la presencia de una modernización endógena al todo social, que se manifiestan, sí con factores de cambio internos, pero también bajo presiones muy fuertes del exterior, de manera que estamos ante visiones alternativas de continuidad y escisión que permean los ámbitos tanto de lo político, lo económico y lo social como de lo cultural.

La cultura, por lo menos en Latinoamérica, dice Brunner (1990:38), y ciertamente en México, añadiríamos nosotros, está en pleno proceso de incorporarse a la modernidad, especialmente en la medida que los medios de comunicación la absorben difundiendo continuamente sus promesas de felicidad a través del consumo, para transformarse en el vehículo multiforme de una creciente integración de masas.

Empero, una sociedad moderna, que integra fenómenos de industrialización, de productividad y de informatización a escala global, no puede prescindir de la presencia de ciertas fuerzas sociales e intelectuales que a través de una importante imaginación crítica señalen los efectos devastadores del progreso. 
Uno de ellos, quizás el más trascendente en términos de que corre el riesgo de minar el último reducto que nos separa de la integración absoluta de los mercados internacionales, es el de la cultura. Como indica Javier Esteinou:

Tradicionalmente la construcción del modelo de país que hemos deseado ser en las últimas 5 décadas se ha fundado, en primer término desde la instancia económica; en segundo término desde la fase política; y casi nunca se ha elaborado desde nuestro nivel cultural de la sociedad (Esteinou, 1991:11).

Ello se debe quizás, a que no hemos alcanzado a sermodermos en el renglón cultural, ya que como dice Brunner (1992), no existe modernidad allí donde los públicos consumidores de los productos culturalesno alcanzan un cierto grado de autonomía local, y cuando no existe una cultura nacional capaz de expresar la modernidad.

Esto querría decir, que para ser modemos culturalmente deberíamos poder producir y defender nuestra propia cultura, puesto que una de las características más importantes del hombre moderno, tal y como filosóficamente se le describe, es la posibilidad de reflexión del sujeto, que a su vez lo posibilita para expresarse y aceptar la pluralidad de los discursos, e incluso generar acción y participar como sujeto político.

Resulta increible pensar en que la modernidad haya dejado de lado la esfera cultural, y que el Estado mexicano no haya contemplado mecanismos modernizadores de la cultura, cuando que:

Con ello, al considerar la cultura comoelementode lujo se ha ignoradoque los proyectos de desarrollo nacional sólo tienen sentido, o no lo tienen, si son expresiones de un proyectocultural. Hay que considerar que no hay desarrolloen abstracto. Elcrecimiento y la transformación de los grupos humanos concretos siempre se da en función de una historia, un presente y un futuro deseable, a partir de su propia peculiar visión del mundo, de su sistema de valores, de sus conocimientos y formas de organización, de sus deseos y esperanzas; en fin, de su cultura. Por ello, la cultura no es una dimensión o un elemento más del desarrollo sino el marco general en el que éste se ejecuta, y por el cual, se realiza. En síntesis, 'la cultura' le da al proyecto nacional su razón de ser. Haza Remus (1988), citado por Esteinou (1991:12).

Sin embargo, la modernidad, como indica Brunner, significa cosas bien distintas: significa que los procesos de comunicación se masifiquen a través del mercado; que el consumo simbólico esté articulado a procesos formativos organizados para 
toda la población; que el uso de conocimientos e información vincule de un modo cada vez más central las distintas esferas separadas de la sociedad: la produción económica con la política y a ésta, como vehículo de hegemonías, con el mercado. No es extraño entonces, que la arena de la cultura, fuera de la modernización económica y de la supuesta modernización política, haya sido aparentemente dejada de lado, cuando en esencia, ha sido la primera en participar del proceso, ya que de hecho, la globalización de los mercados culturales se mueve por delante de la globalización de los mercados económicos y de la política (Brunner, 1992:23).

Lamentablemente, como indica Octavio Paz(1967:170), "la modernidad cortada del pasado y lanzada hacia un futuro siempre inasible", vive al día: no puede volver a sus principios y así, recobrar sus poderes de renovación. De manera que, la modernidad siempre etérea y joven se encuentra en permanente conflicto con la cultura, que insiste en recordarle elementos de su pasado, en cuestionar sus visiones de futuro, y por lo mismo, amenaza con poner en riesgo los avances propuestos por la modernidad.

En México coexisten fuerzas que arrojan a nuestro país hacia la modernidad, con otras que le anclan a un pasado tradicional esencial. Dichas fuerzas son impulsadas a través de diversos mecanismos modernizadores que funcionan como instrumentos de respuesta ante dos elementos que son consustanciales a la modernidad: la continua complejización de las demandas sociales y la incertidumbre.

La modernización, ese movimiento a cuya cabeza se encuentra el Estado, resulta ser la herramienta que rearticula las diversas demandas y las distintas respuestas, abre y cierra las válvulas de escape y dirige las fuerzas sociales en la dirección programada. Empero, aunque la dirección pueda estar trazada, no todos los mecanismos operan con la misma fuerza y con el mismo empuje. Así por un lado, en nuestro país la modernización económica, impulsada abruptamente y con tiempos de respuestas establecidos internacionalmente, ha sido una modernización autoritaria; la modernización política, aunque marcada por sus propios tiempos y sus propios desafíos, se encuentra en transición, pero más que para incorporar y dar voz a nuevos actores políticos al proyecto de modernidad, para conducir a la sociedad mexicana a un relanzamiento pleno del mercadoy de las clases dominantes a ejercer una total hegemonía estatal con tintes democratizadores, por lo que en ese sentido ha quedado rezagada, al punto de constituirse en una premodemidad política; y por lo que respecta a la arena cultural, ésta es la más acelerada de todas, ya que lejos de asumirnos estables en la aceptación de una modernidad cultural 
que implicaría una apropiación del producto cultural y de la aceptación de la pluralidad de los discursos, hemos eclipsado socialmente el momento moderno y súbitamente hemos pasado al instante efímero de la masificación de los discursos y del acercamiento a la sociedad transparente de la información, en la que conviven algunos elementos y valores tradicionales, por lo que nos hemos convertido en culturalmente posmodernos.

\section{Identidad cultural y fusión posmoderna}

En la frenética variedad del mundo moderno aparece de pronto, con rara insistencia el tema de la identidad. Como si el desacostumbrado número de las opciones que se nos ofrecen recodara a nuestra alma que, en ocasiones, la abundancia va de la mano de la desintegración, y requirieramos entonces un escudo que preservara nuestra memoria, las hazañas realizadas por nuestros ancestros, evitando el olvido de las obras del ingenio humano que confieren sentido de pertenencia y nos llevan a admirar la región o nación de nuestro destino (Flores Olea, 1993:21).

Uno de los elementos que hemos introducido aquí como correlato de la modernidad, es la identidad nacional. Es la identidad, primero cultural y luego nacional, la que nos define como sustancialmente diferentes dentro del torrente de la modernidad.

Aún cuando la modernidad sea un punto de luz al otro lado de la orilla, y diversos sean los mecanismos modernizadores que tiendan a llevarnos hacia ella, hay instantes en las que nos interesa, nos es esencial voltear la mirada hacia el punto de partida. Son constantes, por tanto, las referencias hacia el tema de la identidad, entendida como la necesidad social de no diluirse en el proceso, y la conveniencia política de identificar a la nación con el proyecto modernizador.

A lo largo de nuestra historia, en México ha habido numerosas discusiones en torno al tema de la identidad nacional, particularmente en períodos en que políticamente el proyecto de nación, se definía esencialmente como un proyecto modernizador. Samuel Ramos, Leopoldo Zea, Antonio Caso, José Vasconcelos, Octavio Paz, Carlos Fuentes, Carlos Monsiváis, son algunos de los pensadores que desde distintos ámbitos, particularmente el de la filosofía, han debatido el tema de la identidad nacional. Sin embargo, en este momento quizás sea Roger Bartra (1987:238), quien mejor nos sirva al propósito de indicar que el debate sobre la identidad nacional y la creación de los mitos nacionales, no hace sino reflejar ese 
reacomodo social que se da en presencia de la modernidad, cuando adaptando las ideas de Clausewitz, el gran teórico militar del siglo XIX, dice:

Los mitos nacionales no son un reflejo de las condiciones en que vive la masa del pueblo ni una diversión falsa (ideológica) de la conciencia. Más bien, como parte de la cultura son, digamos, la prolongación de los conflictos sociales por otros medios. ${ }^{2}$

Existe por un lado, ese proceso continuo que significa día con día hacer la mexicanidad; pero de la misma manera existe la necesidad de la formación del mito de la mexicanidad, como correlato político de una idea de nación, creada para satisfacer el discurso de la unicidad social necesario en todo proceso de modernidad.

Es evidente también que existen muchos Méxicos, y que somos un país plural en donde cohabitan modos de cultura distintos. No obstante, hay una pugna por definir y proteger nuestra identidad cultural en presencia de la redefinición de nuevos proyectos de nación, o de la formación de una nueva identidad nacional. De manera que, así como siguiendo a Touraine (1990), nos detuvimos a separar el concepto de modernidad del de su correlato de modernización, de la misma manera analíticamente es preciso distinguir las particularidades de la noción de identidad cultural, de las características integradoras que el Estado propone como parte de una identidad nacional.

Esta precisión conceptual nos prueba ser de gran utilidad, en la medida en que nos posibilita aclarar el debate teórico que se ha venido dando en torno del tema de la identidad:

Quienes hablan de la necesidad de preservar una identidad para nuestro país, confunden términos, en la medida en que observan el peligro de que la fusión económica - por ejemplo en vísperas de la aprobación del Tratado Trilateral de Libre Comercio con Estados Unidos y Canadá - implique una fusión política y cultural, cuando que en realidad están llevando a cabo una furiosa defensa de la identidad nacional. ${ }^{3}$ Quienes defienden la integración, generalmente lo hacen sobre la base de aclarar que toda cultura necesita revitalizarse por contacto con otras, y que aquella cultura que no permite la inclusión de elementos nuevos, aún perte-

2 Citado también por Gutmann (1993:36).

3 Carlos Monsiváis por ejemplo, ha hecho en repetidas ocasiones una importante crítica a las formas de fusión de la identidad del mexicano con otras influencias, particularmente la estadounidense, al punto de decir, que ya tenemos aquí "la primera generación de estadounidenses nacidos en México". 
necientes a otras culturas, perece; de esta forma están en esencia refiriéndose a lo que aquí hemos dado en llamar precisamente identidad cultural. ${ }^{4}$

Remitámonos nuevamente a la noción de cultura como alimento esencial de nuestros pueblos, y a la emisión continua de productos de cultura, y estaremos en presencia de una identidad cultural viva y cambiante. Volteemos la mirada ahora a los proyectos de nación que nuestro país ha instrumentado a lo largo de las diferentes vidas de su sistema político, parte como elemento unificador de los discursos, y parte como elemento constructor de un imaginario social de progreso y modernización, y estaremos en presencia de nuestra identidad nacional. Descubramos ahora los nexos que vinculan una y otra concepción, fundiéndolas a veces en una sola, y apuntaremos a destacar uno de los mecanismos modernizadores más importantes en operación: el de la construcción de los discursos de la modernidad a través de los medios de comunicación colectiva.

Quienes apuntan hacia el problema de la identidad en cualquiera de sus dos acepciones, sea cultural o nacional, quizás se quedan cortos al señalar sólo una parte del problema; el análisis debiera centrarse en las formas en las que estructuralmente se entrelazan los mecanismos culturales con los mecanismos de cooptación política y económica.

Quizá la discusión debería centrarse más en términos de la discusión de un proyecto nacional, que aglutina en sus propuestas la premisa inherente de una fusión cultural característica de una modernización esencialmente económica; y claro, - frente a las protestas de algunos sectores intelectuales ante las propuestas de ese nuevo proyecto modernizador - en la manifestación clara, una vez más, de una preocupación no tanto cultural sino política, relativa a la ausencia de participación social en la definición de un proyecto modernizador nacional.

Si revisamos el proceso de creación de identidad nacional por el que atraviesa nuestro país, y la participación del Estado contemporáneo en la creación de semejante identidad, podemos identificar cincoetapas fundamentales según Carlos Monsiváis (1987): en la primera (1910-1920), los cambios que se dan no significan el fin de un sistema económico, pero denuncian las presiones de una revolución social y cultural en torno al nuevo trato del individuo con la nación; en la segunda

4 Al respecto es factible ver la obra del antropólogo Néstor García Canclini, o bien las ideas manifestadas por el escritor carlos Fuentes, quienes ven en la próxima implementación del Tratado de Libre Comercio, la posibilidad de un crecimiento cultural para México. 
(1920-1940), el Estado decide convertir el nacionalismo en la educación cívica y moral de las mayorías a través del desarrollo de una mitología postrevolucionaria, que es el método unificador sin el cual no procede la modernización; en la tercera, (1940-1960), el elemento importante es la campaña de la Unidad Nacional que permite la industrialización acelerada que faculta al desarrollo nacional. (Para arribar al Progreso sólo se requiere unirse con firmeza en torno a la Nación-Estado). En la siguiente etapa (1960-1980), se agudizan las presiones de la modernización sobre el nacionalismo, sin embargo, apoyado en el culto fanático a la tecnología, se solidifica el poder del Estado, se extiende la cultura urbana, se aceptan un conjunto de mitos y costumbres internacionales debido en gran medida a la presencia de los medios de comunicación masiva. Y por último, en la quinta etapa, "la de la crisis", iniciada en 1980, el nacionalismo se enfrenta primero al reclamo de una democratización violenta de la vida nacional que comienza a manifestarse desde el 85 , y que se torna en un nacionalismo exacerbado porque en el fondo nunca creyó en las alternativas. Monsiváis no continúa su análisis del nacionalismo mexicano porque escribe su ensayo antes de las elecciones del 88 , y porque en ese momento el Estado mexicano no reconvertía todavía los rastros de un nacionalismo resurrecto en el Programa Nacional de Solidaridad, ni en las perspectivas de la entrada definitiva de México a la modernidad a través de la firma del Tratado de Libre Comercio para América del Norte; pero si nosotros extrapoláramos su planteamiento, tal vez podríamos acotar que en esta última etapa, el nacionalismo mexicano se ha eclipsado en aras de una identidad postnacional que no reconoce fronteras culturales, sino que se funde con las otras identidades: las del consumo, las de la tecnología, las de la globalización.

Es ésta quizás el tipo de identidad postnacional a la que se refiere Roger Bartra (1991:17-19), cuandodice que, para países comoelnuestro, la problemática consiste en la superación democrática del autoritarismo aunado al atraso económico, lo cual implica el problema de superar el orgullo nacionalista para construir una identidad postnacional, basada en las formas pluriculturales y democráticas de una vida cívica que forme parte del mundo occidental. Para Bartra, la modernidad, junto con el nacionalismo, está herida de muerte y no tenemos más remedio que enfrentar a la posmodernidad del fragmentado mundooccidental del que formamos parte.

Ahora bien,lo que Bartra supone es que el avance de nuestra identidad cultural marcha a la par del avance de nuestra identidad nacional. Si bien, en la arena 
cultural hemos incluso desarrollado procesos culturales de adopción, asimilación, e hibridización de las culturas, en el aspecto político, la transición hacia una cultura política postnacional que de paso a una rica y democrática multiplicidad, se enfrenta todavía a crisis de gobernabilidad y legitimación del sistema. Sobre esto último, recordemos además, las palabras de Carlos Fuentes cuando dice que, es cierto, nuestro país tiene que reanudar un desarrollo económico, pero éste ya no puede privarse de su escudo político que es la democracia; ni de su escudo social que es la justicia; ni de su escudo mental que es la cultura. En este último caso, la cultura actúa como elemento de adhesión e identificación - léase identidad - pero sólo en la medida en que su variedad sea respetada y pueda manifestarse libremente.

Fuentes (1992) apunta que la modernidad ha sido nuestro fantasma constante, nos ha acompañado a lo largo de toda nuestra historia. La realidad, dice el autor, es que tenemos que hacer cuentas con nuestro pasado para enfrentarnos a esa historia y asumir lo que somos. Mientras no asumamos lo que somos no podremos seguir adelante. Ahora bien, parte del reconocimiento de la propia identidad estriba en el reconocimiento del otro, en la conciencia de lo extraño, que acaba por enriquecernos.

Al respecto, el antropólogo Néstor García Canclini (1992:39) explica que el desarrollo cultural de las sociedades ha requerido siempre disponer de tiempo para renovar la información que se tiene, además de conocer otros paradigmas y otras formas de vida y añade que, en gran medida, el esplendor de nuestras culturas antiguasfue el resultadode largas búsquedas de conocimiento yexpresión simbólica realizadas precisamente con la acumulación y la paciencia de los siglos.

La problemática de la apropiación intercultural en nuestro tiempo, radica en la aceleración de los procesos producto de la nueva tecnología de información, y particularmente en un momento como el actual en que las identidades son políglotas, multiétnicas, migrantes y hechas con elementos de varias culturas, cuando por primera vez en esta segunda mitad del siglo $\mathrm{XX}$, la mayor parte de los bienes y mensajes que recibimos no son producidos en el propio territorio, ni llevan vínculos que los liguen a la comunidad nacional, sino que más bien pertenecen a un sistema desterritorializado (García Canclini, 1992:32-33).

García Canclini observa que, en el caso de la globalización cultural a la que se ha obligado nuestro país por su entrada a la Comunidad Económica de América de Norte, vía el Tratado de Libre Comercio, lo que se da es una trasnacionalización y una globalización de la cultura. 
Ahora bien, en una situación de interculturalidad como esta, las culturas se configuran no sólo por las diferencias entre culturas desarrolladas de manera desigual, sino por las maneras desiguales en que los grupos se apropian de elementos de varias sociedades, los combinan y los transforman. El objeto de estudio de una situación tan particular como la que ahora se nos presenta, dice García Canclini (1992:34), debe ser no sólo la diferencia, sino también la hibridación.

Otro antropólogo, Guillermo Bonfil Batalla, en uno de sus últimos trabajos (1991:10), apuntó directamente sobre las consecuencias culturales del Tratado de Libre Comercio para nuestro país; en dicha intervención decía:

En el terreno cultural, en efecto, una de las posibilidades más sugerentes y positivas del TLC sería la de facilitar la circulación más libre de ideas y de los valores alternativos que éstas conllevan. Por decirlo en términos telecistas: una oferta mayor y más divertida de ideas y valores capaces de dar sentido a nuestra existencia. (...)El problema no está en el TLC (...) sino en los mecanismos sociales y políticos que seamos capaces de instrumentar en la sociedad mexicana para asegurar el mejor uso posible de esa prerrogativa en beneficio autentico de nuestra propia sociedad plural.

Sin embargo, Bonfil Batalla (1992a:18), se pregunta hasta qué punto la identidad nacional, forjada en nuestro pueblo a resultas de la Revolución Mexicana sedimentó en nuestra cultura una idea específica de soberanía nacional, y de qué manera el proyecto nacional que se perfila hoy, modifica totalmente ese sustrato cultural:

La apertura del mercado, que ya es un hecho consumado con o sin TLC, tiene implicaciones culturales de gran trascendencia. La opción de promover una oferta cada vez mayor de productos y más variados es, en el fondo, la opción por un cierto modeio de vida: solamente uno, particular y único, entre otros muchos posibles. En el contexto actual, ese modelo es el de una sociedad de consumo, que valora la adquisición, la acumulación y la renovación de bienes como el propósitomás alto de la existencia social e individual. En una sociedad como la nuestra, en el futuro previsible, este modelo producirá, además, mayor desigualdad: una concertación más alta y una marginación más extendida.(...)

No es un problema que se limite a borrar barreras arancelarias: va mucho rinás alla porque implica asumir un modelo de sociedad para el futuro. Ese modelo ¿lo estamos adoptando libre y soberanamente los mexicanos? inos es impuesto por la fuerza de las cosas, por las leyes ineluctables de la historia, por un destino indiscutiblemente manifiesto al que sólo cabe someterse fatalmente? 
Quizás lo que finalmente sucede, no es tanto que éste sea un modelo adoptado libre y soberanamente por los ciudadanos de una nación, sino que, de tiempo atrás, el germen de toda sociedad moderna en gestación, la reproduce posibilitando la coexistencia cultural de elementos tradicionales, junto con los productos masivos de consumo cultural que arroja la modernización; en esa medida, tal y como sugiere Edgar Morin (1962a, 1962b), las sociedades modernas son "policulturales" en el sentido de que agrupan en su seno tanto los fenómenos culturales del consumo masivo, como a elementos de la cultura nacional, de tal manera que la resultante acaba siendo una cultura cosmopolita por vocación y planetaria por extensión; 0 dicho de otra manera, una cultura producto de una dialéctica producción-consumo en el seno de una dialéctica global de industrialización planetaria.

Dicha industrialización planetaria es el punto de llegada de toda sociedad moderna, es la meta de todo proceso de modernización; el momento mismo de la posmodernidad como instante creador excelso de todo lo moderno. Se ha sugerido aquí, sin embargo, que las metas no se alcanzan en la misma proporción, en todos losámbitos yen todos los casos: en el casode México, los procesos de modernización económica nos han llevado a alcanzar una modernidad autoritaria, impuesta como proyecto nacional; mientras que la modernización cultural, que es un hecho consumado, se perfila, con o sin TLC, apuntando hacia la posmodernidad.

Esta paradoja de desarrollos desiguales pero compartidos, se aclara cuando tomamos precisamente el concepto de hibridación intercultural de García Canclini, y cuando se siente, desde la óptica de Bonfil Batalla, que aunque la lógica modernizadora funcione desde la perspectiva económica, desde la perspectiva cultural cuesta mucho trabajo pensar que el TLC proponga un pacto entre desiguales, no sólo por su riqueza o por su grado de desarrollo tecnológico, sino por su cultura, resultado de historias diferentes.

Para el caso de México, hemos de integrar adicionalmente al análisis, el hecho de que con el TLC no únicamente estamos entrando en una relación trilateral de desigualdades económicas y culturales, sino que de antemano, incluso al interior de nuestro propio país, los procesos de modernización y culturización están ya produciendo fenómenos de hibridación adyacentes; dicho de otra manera: observamos la coexistencia de acercamientos paralelos de diversos sectores, pero con distintos grados de avance a la modernidad. El análisis de la desigualdad de García Canclini nos aclara la manera como estos grados distintos de modernidad pueden 
coexistir al interior de sociedades, en donde la presencia de elementos tradicionales con elementos modernos, ha producido interesantes procesos de hibridación.

Los medios de comunicación juegan un importante papel en este proceso, ya que entre otras cosas, la redistribución masiva de los bienes simbólicos tradicionales por los canales electrónicos de comunicación, genera interacciones más fluidas entre lo culto y lo popular, lo tradicional y lo moderno (García Canclini, 1990:183).

García Canclini indica que, la perseverancia y los reacomodos de tantas costumbres y formas de pensamiento luego de quinientos años de cambios, primero por la dominación colonial y luego por los varios proyectos de modernización, hacen suponer que el Tratado de Libre Comercio no va a borrar la identidad cultural de nuestro país (1992:25). No obstante, también apunta que es necesario considerar cuidadosamente las asimetrias y dominaciones que a menudo regulan los vínculos interculturales, para lo cual habrá que observar muy de cerca los circuitos de desarrollo cultural de nuestro país, entre los que se encuentran en forma determinante los medios de comunicación, ya que la cultura nacional depende en gran medida de las transformaciones que se den en estas importantes áreas de influencia.

El autor aclara que si bien nuestra identidad cultural ha soportado importantes embestidas, si no se desarrollan políticas nacionales en las comunicaciones masivas y en relación con las tecnologías existentes de información y comunicación, la capacidad de sostener aspectos claves de la identidad yun desarrollo autogenerado, disminuirán velozmente (1992:37).

¿Será que nuestra identidad cultural representa el último reducto contra el mimetismo o la fusión cultural que traerá consigo el Tratado de Libre Comercio, o bien, que como parte de nuestra entrada a la modernidad tendremos que asumir procesos de hibridización permanentes que terminen por difuminar nuestros rasgos culturales bajo la sombra de una supuesta identidad postnacional?

\section{Medios de comunicación, globalización e imaginario social}

Lo que resulta evidente del planteamiento anterior, es la necesidad de revisar cuidadosamente el papel desempeñado por los medios de comunicación en todo el proceso, ya que la acción de los medios de comunicación es vista, en sí misma, como ejemplo vivo y actuante de la modernidad. 
La capacidad informativa de las nuevas tecnologías, la simultaneidad en la que aparecen los discursos, la globalización instantánea que permite a un mismo mensaje recorrer al mundo en cuestión de segundos... todo ello representa la faceta encandiladora de la modernidad. De hecho, la simultaneidad de la comunicación se ubica en el centro mismo del fenómeno de la modernidad, y lo que es más, la vigencia en la unicidad de los discursos nos lanza violentamente hacia las posibilidades de una posmodernidad en acto, que es en esencia, el instante creador de la modernidad.

Lo anterior permite conducir a la sociedad, a una sociedad en donde la comunicación es ilimitada, o como también se le conoce, a una "sociedad transparente"; término a través del cual quieren ponerse de manifiesto la pluralidad de los mecanismos y armazones internos con los que se construye la cultura (Vattimo, 1990).

Ahora bien, simultáneamente a los fenómenos de discusión, análisis y recrudecimiento del debate sobre las identidades nacionales y culturales, y junto con los procesos de resistencia cultural, se están dando procesos en los cuales las expresiones culturales propias de los pueblos parecen diluirse en el remolino de la instantaneidad o la "transparencia" de la información; en donde acercándonos al momento sublime de la posmodernidad, el sujeto social en contacto con la información del momento, puede estar con otros sujetos a miles de kilómetros de distancia, todos alejados de una idea única de nación o de cultura, y en donde las distintas manifestaciones y perfiles de la cultura se encuentran en una sola expresión tecnológica universal: la de la instantaneidad de la comunicación.

Bonfil Batalla indica, que ante un fenómeno como este, en donde se observa la globalización no sólo de las comunicaciones, de los mercados, de los capitales y de la tecnología, las decisiones que cuentan se toman en otra esfera, es decir en aquella en la que pesan más los intereses trasnacionales.

Los Estados nacionales tienden a formar bloques, nuevas alianzas para ocupar una parcela en la economía global. El mundo se achica, la comunicación instantánea no respeta fronteras (Bonfil Batalla, 1991b:15). Y entonces, agregaríamos, la dinámica de la política es otra. Así, la modernidad acerca al sujeto a la idea de Nación; la posmodernidad lo funde con la aldea global, y lo nutre con la posibilidad de una identidad social universal, postnacional.

Resulta pertinente apuntar, sin embargo, que en estas negociaciones en torno a las nuevas alianzas entre bloques, el tema de la identidad es poco tocado, 
seguramente por ser muy controvertido; y quienes lo han tocado, lo han hecho o bien para reafirmar que desean preservar su identidad que, frente a la promesa de una identidad universal, postnacional, parece estar amenazada, o bien para subsumirla por completo. Por ejemplo, al principio de la negociación trilateral para el Tratado de Libre Comercio de América del Norte, Canadá claramente apuntó que se oponía a incluir a sus industrias culturales en las negociaciones del TLC, ya que dicha área era considerada "una parte vital de la conservación de nuestra identidad cultural". 5 Estados Unidos indicó que "si Canadá insiste en la exclusión de las industrias culturales, entonces debería modificarse el tratado tripartita y firmarse un acuerdo sólo con México". ${ }^{6}$ Mientras que, por loque respecta a nuestro país, el Secretario de Comercio y Fomento Industrial y jefe del equipo negociador, Jaime Serra Puche, indicó en controvertida declaración que: "Respecto de la cultura, es un asunto que no es tan relevante para México".

El resultado definitivo en el documento final hace alusión, sólo en forma muy escueta, a las industrias culturales, al establecer simplemente que "cualquier medida que se adopte o mantenga en lo referente a las industrias culturales, salvo lo previsto explícitamente en el artículo 302, 'Trato nacional y acceso de bienes al mercado - Desgravación arancelaria', y cualquier otra medida de efectos comerciales equivalentes que se tome como respuesta, se regirá conforme a este Tratado exclusivamente por lo dispuesto en el Acuerdo de Libre Comercio entre Canadá yEstados Unidos. Los derechos y obligaciones entre Canadá y cualquier otra Parte en relación con dichas medidas serán idénticos a los aplicables entre Canadá y los Estados Unidos" (Secofi, T. I:337).

Lo anterior parece indicar, que Canadá doblegó su postura de defensa de su identidad cultural, ante las presiones comerciales de sus otros dos socios en la negociación.

Es así que, pese a la importancia de las industrias culturales, incluidos los medios de comunicación, muy poco se les ha tomado en cuenta para la instrumentación de una política cultural que contemple nuestra nueva relación trilateral con los

5 Como se expresa en el artículo: "Se opone Canadá a incluir su industria cultural en el TLC" (1991). Unomasuno, 17 de mayo.

6 "Estados Unidos no aceptará que se excluya el tema de la cultura del TLC" (1991). La Jomada, 13 de junio.

7 Conferencia de prensa del 12 de junio de 1991, comentada en diversos diarios nacionales. 
vecinos del norte, o lo que viene a significar nuestra entrada definitiva a la modernidad.

Por ejemplo, el TLC dice a la letra:

industrias culturales significa toda persona que lleve a cabo cualquiera de las siguientes actividades:

(a) la publicación, distribucion o venta de libros, revistas, publicaciones periodicas o diarios impresos o legibles por medio de máquina, pero no incluye la actividad aislada de impresión ni de composición tipográfica, ni ninguna de las anteriores;

(b) la producción, distribución, venta o exhibición de grabaciones de películas o video;

(c) la producción, distribución, venta o exhibición de grabaciones de música en audio o video;

(d) la publicación, distribución o venta de música impresa o legible por medio de máquina; 0

(e) la comunicación por radio en la cual las transmisiones tengan el objeto de ser recibidas por el público en general, asi como todas las actividades relacionadas con la radio, televisión y transmisión por cable y los servicios de programación de satélites y redes de transmisión (Secofi, T. I:336).

Tal definición de lo que constituye una industria cultural, excluye por supuesto otras instancias productoras de cultura, como las escuelas, los museos, los espectáculos, etc., que de hecho contribuyen enormemente, junto con los medios de comunicación, a crear el imaginario social apropiado a la modernidad. En este sentido, es que se ha desconocido la trascendental y profunda acción que estas industrias culturales - definidas de otra manera, y no a la manera telecista de la negociación comercial - realizan permanentemente sobre la conciencia de los públicos mayoritarios del país para conformar una cultura cotidiana proclive a la integración con el resto de Norteamérica.

Como indica Javier Esteinou (1992), existe la necesidad inminente de reflexionar sobre nuestra cultura y la acción que deben ejercer los medios de comunicación, para conservar su esencia nacional orientada hacia el desarrollo de nuestra conciencia dentro de la dinámica de acelerado cambio modernizador que vive el país; pues el proceso de la globalización mundial nos lleva a la creación de un nuevo orden cultural que modificará los contenidos y las fronteras ideológicas de los actuales estados nacionales. De lo contrario - continúa este investigador - el alma cultural de nuestra sociedad correrá el gran riesgo de quedar sepultada por los 
nuevas espejismos de la modernidad y sus derivados simbólicos parasitarios de esta nueva fase del desarrollo de la sociedad capitalista internacional.

Por otra parte, es notable como día a día los medios de comunicación gestan un imaginario social proclive a la modernización y a los mecanismos de la globalización económica. Nuestra niñez y juventud se ven sometidas a las atractivas ofertas del mercado capitalista por un lado, y por otro a los reclamos naturales de su identidad nacional. Esto ha provocado una enorme contradicción entre la sensibilidad que el Estado mexicano siembra por la mañana en las conciencias de los niños, jóvenes y adultos, con muchísimos esfuerzos - a través de la educación formal- y que se destruye por la tarde y noche mediante la acción deseducativa de los avanzados canales de comunicación, particularmente la televisión (Esteinou, 1991:16-17).

¿Es ésta acaso una reacción natural, producto de la esquizofrenia a la que nos lanza la modernidad, cuando simultáneamente al desear obtener las maravillas que nos promete la modernidad, nos encarnamos en la identidad otra, en la extraña, en la postnacional, para sentirnos ubicuos, integrados a la información planetaria, mientras que, paralelamente defendemos con uñas y dientes los últimos resquicios de nuestra identidad?

No hay que olvidar que aquí hemos propuesto una distinción básica entre dos conceptos de identidad: por un lado, la identidad nacional, misma que está sujeta a cambios puestoque proviene de los proyectos de Nación planteados por elEstado; y por otro lado, la identidad cultural que es dinámica y cambiante, por lo que permanentemente adopta, adapta, excluye, incorpora y modifica elementos culturales diversos en un continuo proceso de hibridación. ¿Cuál de estas identidades es la que hay que defender? ¿Será que una cobra preeminencia sobre la otra? Parecería ser que la segunda, la identidad cultural, constituye nuestra única posibilidad real de escapar al mimetismo, a la fusión cultural plena, ya que la primera, la nacional, es una identidad impuesta, que responde a la figura del Estado puesto que emana de éste; mientras que la cultural, se desdobla y se rearticula para permitir la incorporación de nuevos elementos culturales, pero sin dejar de sostener una permanente resistencia, hacia los mecanismos impuestos por los proyectos nacionales, que ahorcan la esencia cultural de cada uno de los pueblos.

México no va a dejar de ser lo que es ante la inminencia del Tratado trilateral de Libre Comercio; quizá Carlos Fuentes tenga razón cuando dice (1992b): 
La identidad nacional mexicana es muy fuerte, más que la estadounidense. Son ellos los que deben temernos, la lengua castellana, la continuidad cultural y la pluralidad de tradiciones (indígena, espanola, mestiza, mediterránea) acentuarán el mestizaje estadounidense. Para nosotros la policultura no es un problema.

Sin embargo, también es un hecho que ante la influencia intercultural nuestro país no quedará incólume, su identidad cultural continuará recomponiéndose en presencia de elementos culturales ajenos, ante los cuales se adopta una mecánica de imitación conjunta a procesos de resistencia; el resultado: la hibridación cultural de la que habla García Canclini.

Ahora bien, qué tanto esta nueva identidad cultural recompuesta, responderá al proyecto de nación y a la figura de identidad nacional que el moderno Estado mexicano plantea para todos nosotros, eso está por verse.

Lo más probable es que ambas identidades, la nacional y la cultural se combinen para formar parte del imaginario social al que todos contribuimos y del que todos nos alimentamos culturalmente. ¿Cómo discernir en medio de esos cruces de identidades qué es lo propio de la cultura de un pueblo, y qué es lo que ha sido generado por las tecnologías comunicacionales? La cuestión aquí radica entonces, en determinar qué elementos culturales y provenientes de qué orígenes, son los que mayoritariamente participan, qué sujetos, qué actores sociales y políticos, son los que operan en la conformación de esos discursos.

El momento coyuntural que vive nuestro país, sintetiza el ejercicio de muchas fuerzas que se vienen gestando desde nuestra supuesta constitución como país moderno - probablemente desde la revolución de Independencia - sin embargo, es en este decenio que entran en receso - como lo hizo ver el proceso del 6 de julio de 1988 - los entendimientos hacia afuera (Ruiz Massieu, 1990:54). O dicho de otra manera, hay una recomposición de los imaginarios sociales, entre los que destacan claramente los valores de identidad nacional y cultural.

Los medios de comunicación desempeñan un papel preponderante en la construcción de dichos imaginarios sociales; no en balde los ideólogos del partido en el poder han volteado los ojos hacia estos interlocutores tecnológicos con miras a determinar los espacios que han de ocupar en las próximas décadas. Al respecto, José Francisco Ruiz Massieu, quien no se considera a sí mismo ni el político ni el intelectual, sino funcionario que pone su pensamiento en acción, opina: 
Con los medios colectivos de comunicación, el nuevo entendimiento no podrá ignorar que son una expresión del pluralismo social, y con cautela tendrá que hacerse frente a las relaciones económicas entre ellos, el Estado y otros poderes; y entre los medios y los propios periodistas.

Con Estados Unidos el entendimiento, es seguro, oscilará entre la vinculación eficiente de México en el mercado norteamericano -que sirva mejor a nuestro desarrollo y a la soberanía- y pondere las tendencias multipolares; el respeto puntual a la independencia y la protección eficaz de los intereses mexicanos.

La recomposición de la relación con los intelectuales estará condicionada por la posibilidad de formular e implantar una gran política cultural, que bajo el signo del pluralismo y la libertad, estimule la creación, y revierta el proceso de depauperización de ese sector. En todo caso, estará presente que si bien, el político se ocupa profesionalmente de la política, y el intelectual, por oficio, se preocupa de ella, la política es una forma cultural, y la política cultural es capítulo imprescindible del proceso politico. (Ruiz Massieu, 1990:55). ${ }^{8}$

Si Ruiz Massieu tiene razón y el partido en el poder reconoce la importancia de la labor de los medios de comunicación para el proyecto de modernización del país, y si es cierto que una gran política cultural sería imprescindible en todo este proceso, justo es analizar detenidamente las implicaciones de una posible política cultural en este sentido.

Una forma de aproximarse, por lo menos de manera inicial, al proyecto de desarrollar una política cultural para nuestro país, sería - como plantea García Canclini (1990:184), basándose en lo que propone a su vez Raymond Williams en el sentido de construir un criterio de lo rescatable más que por la oposición entre lo tradicional y lo moderno, por la distinción entre lo arcaico, lo residual y lo emergente; siendo lo arcaico, lo que pertenece al pasado y es conocido como tal por quienes hoy lo reviven; lo residual, lo que se formó en el pasado, pero que todavía se halla en actividad dentro de los procesos culturales, y lo emergente, que designa los significados y valores, nuevas prácticas y relaciones sociales. Sólo de esta forma, es que podríamos intentar un análisis a fondo, que nos permitiera ver de cerca nuestra identidad cultural, para diferenciarla claramente de la identidad nacional, y de las otras identidades que nos propone el proyecto modernizador.

No es propósito de este trabajo delimitar los parámetros de acción y los alcances de una política de esta naturaleza; sentimos que todavía nos hacen falta muchos elementos para poder siquiera atisbar el complejo panorama para proponer la

8 El énfasis es mío. 
gestación de una política cultural viable; sin embargo, lo que sí nos queda claro es la importancia de la intersección entre los ejes modernidad, identidad y modernización para México, así como la certeza de que vale la pena continuar desentrañando sus posibles cruces, con la esperanza de lograr en el proceso, una mayor claridad para el camino.

Es cierto que cerrar los ojos a la globalización sería cerrarnos la puerta al juego de las grandes alianzas de bloques, y ello más que detener nuestro desarrollo, nos condenaría al aislacionismo y al anquilosamiento; sin embargo, al zambullirnos tan de golpe en el océano de la modernidad, probablemente hemos perdido de vista la otra orilla, sin detenernos a analizar los diferentes estilos de vida y modelos culturales, a través de imágenes de todo tipo que - como dice Bonfil Batalla (1991b:16-17) - ocupan los espacios de nuestra vida cotidiana y van desplazando paulatinamente nuestra "cultura de lo real", (la que se sustenta en las circunstancias de la sociedad en la que se vive y a la que se pertenece), por una cultura imaginaria que se construye a partir de la aspiración de cambiar de realidad, -léase no sólo ser modernos sino posmodernos-, que es muy diferente a la aspiración de cambiar la realidad.

\section{Referencias bibliográficas}

BARTRA Roger (1987): La jaula de la melancolia: Identidad y metamorfosis del mexicano. México: Grijalbo.

(1991): "La venganza de la Malinche: hacia una identidad postnacional". Este país (abril).

BERMANMarshal (1989): "Brindis por la modernidad". En Nicolás Casullo(comp.) El debate modernidad pos-modernidad. (s.d): Editorial Pontosur.

BoNfIL BATAlla Guillermo (1991a): "Dimensiones culturales del Tratado de Libre Comercio". México indígena Núm. 24 (septiembre).

(1991b): Pensar nuestra cultura. Barcelona: Alianza editorial. 
BRUNNER José Joaquín (1990): Tradicionalismo y modernidad en la cultura latinoamericana. Santiago de Chile: Documentos de trabajo FlAcso. Serie Educación y Cultura Núm. 4 (diciembre).

(1992): "América Latina en la encrucijada de la modernidad". En Comunicación, identidad e integración latinoamericana. Memorias del VII encuentro Latinoamericano de Facultades de Comunicación Social. Vol. I En torno a la identidad Latinoamericana.

CAMOU Antonio(1992): “Once tesis sobre la'transición mexicana'.Gobernabilidad y democracia". Nexos Núm. 170 (febrero).

ESTEINOU Javier (1991): La televisión mexicana ante el modelo de desarrollo neoliberal. México: Programa Cultural de las Fronteras/Fundación Manuel Buendía.

(1991): La televisión mexicana ante el modelo de desarrollo neoliberal. México: Fundación Manuel Buendía y Programa Cultural de las Fronteras.

(1992): ¿Hacia el fast track dela desnacionalización mental? Comunicación y cultura social en el neoliberalismo". Revista mexicana de comunicación Núm. 26 (noviembre-diciembre).

FERNÁNDEZ REYES Otto (1993): "El dilema de la modernidad". Suplemento especial de política, El Nacional, 28 de enero.

FLORES OlEA Víctor (1993): "Identidad nacional. Los rostros en movimiento". La jornada semanal Núm. 186, domingo 3 de enero.

FUENTES Carlos (1991a): “Nacionalismo e integración”. Este país (abril).

(1991b): “El TLC no afectará nuestra identidad nacional”. La Jomada, 18 de julio.

_ (1992): "La pasión del futuro". Nexos Núm. 175 (julio). 
GARCIA CANCLINI Néstor (1990): Culturas hibridas. Estrategias para salir y entrar de la modemidad. México: Grijalbo-conaculta.

(1992): "Museos aeropuertos yventas de garage. La cultura ante el Tratado de Libre Comercio". La jomada semanal, s.n., domingo 14 de junio.

Giuly Adolfo (1988): “La otra modernidad”. Nexos Núm. 124 (abril).

GUTMANNMatthew C. (1993): “Culturas primordiales y creatividad en los origenes de lo mexicano". La jomada semanal Núm. 186, domingo 3 de enero.

HAZA REMUS Luis Armando (1988): "Políticas de financiamiento de la cultura". Seminario Política Cultural en México México: Coordinación de Humanidades. Centro de Investigaciones Interdisciplinarias, Universidad Autónoma de México, 8 de noviembre.

HUNTINGTON Samuel (1972): El orden politico en la sociedades en cambio. Buenos Aires: Paidós.

MoNSIVÁIS Carlos (1987): "Muerte y resurrección del nacionalismo mexicano". Nexos Núm.109 (enero).

MORIN Edgar (1962): El espiritu del tiempo I y II. (s.d.).

PAZ Octavio (1967): Corriente alterna. México: Siglo XXI.

RUIZ MASSIEU José Francisco (1990): Ideas a tiempo. México: Editorial Diana.

SECOFI (s.f.): Tratado de libre comencio de América del Norte, Tomo I: anexo 2106.

SUBIRATS Eduardo(1989): "Transformaciones de la cultura moderna". En Nicolás Casullo (comp.) El debate modenidad pos-modenidad. (s.d.): Editorial Pontosur.

TOURAINEAlaine(1990): “Modernidadyespecificidades culturales". EnVertientes de la modernización CEN-PRI. 
TRAYNOR Ken (1992): "The origins of Free Trade Mania. The people of Canada and Mexico do not want free trade, but big business does; big business gets what it wants". En Jim Sinclair (ed.) Canada and free trade with Mexico, Crossing the line. Vancouver: New Star Books.

VATTiMo Gianni (1990): La sociedad transparente. Barcelona: Paidós. 